\title{
EVALUATION OF CAT SCRATCH DISEASE CASES REPORTED FROM TURKEY BETWEEN 1996 AND 2013 AND REVIEW OF THE LITERATURE
}

\author{
Mehmet Uluğ \\ Department of Infectious Diseases and Clinic Microbiology, Private Ümit Hospital, Eskişehir, Turkey
}

\section{SUMMARY}

Background: Cat scratch disease (CSD), the most common cause of chronic lymphadenopathy among children and adolescents, typically features regional lymphadenitis associated with inoculation site due to a cat scratch or bite.

Objective: The aim of this study was to systematically review the articles related to CSD which were reported from Turkey in national and international journals in the last 18 years with a pooled-analysis method.

Methods: The articles related to CSD were retrieved by search of four national (Ulakbim Turkish Medical Literature Databases*) and three international databases (Pub-Med, Science Citation Index (SCI) and Google scholar).

Results: Between the years 1996-2013, CSD cases have been published in a total of 16 articles (4 international, 12 national). These articles which were presented as a case report included a total of 18 CSD cases (38.8\% women, $61.2 \%$ men; median age 16 years). The most common clinicopathologic subtypes of CSD are regional lymphadenitis $(n=9)$, hepatosplenic $(n=3)$ and neuroretinitis $(n=2)$. The most common complaints of patients were swelling $(94.4 \%)$, fever $(61.2 \%)$ and weakness $(50 \%)$ at admission. On exam, the most common signs were lymphadenopathy $(94.4 \%)$, fever (61.2\%), splenomegaly (16.6\%), and skin eruption (16.6\%).

Conclusion: This pooled analysis which enabled the evaluation of a large number of CSD cases, indicated that careful evaluation of clinical findings and histopathological investigation will provide valuable support for diagnosis and treatment of CSD.

Key words: cat scratch disease, lymphadenitis, Turkey

Address for correspondence: M. Uluğ, Private Ümit Hospital, Infectious Diseases and Clinic Microbiology, Batıkent Mah. Gerekli Sok. No: 13, 26140 Eskişehir, Turkey. E-mail: mehmetulug21@hotmail.com

\section{INTRODUCTION}

Cat scratch disease (CSD) is a benign zoonotic infectious disease caused by Bartonella henselae (1). Cats are the main reservoir of $B$. henselae, and the epidemiological investigations have revealed that a history of contact with cats is found in $90 \%$ of CSD patients and the antecedent of a cat scratch or bites is found in $60 \%$ of the patients (2). The majority of the cases have occurred in persons under 20 years of age, usually male, and the number of cases has been consistently reported to peak in autumn and winter months (3).

The common clinical syndrome of regional lymphadenopathy accompanied by fever and other systemic symptoms is referred as typical CSD, and is generally benign and self-limited. Approximately $10 \%$ of the patients will have atypical disease, such as Parinaud's oculoglandular syndrome, neuroretinitis, granulomatous hepatitis and splenitis, osteomyelitis, endocarditis, and encephalitis (4).

Attempting to isolate $B$. henselae is difficult since this culture is not routinely recommended. Due to frequent failure of culture-based methods, diagnosis often relies of histopathological examination of biopsy material in which organisms may be visualized using the Wartin Starry silver staining method (2). However, serology is the best initial test and can be performed by indirect fluorescent assay (IFA) and enzyme immunoassasy (EIA) (5).

Most cases of CSD in immunocompetent patients resolve spontaneously. Antibiotic use is controversial, but successful results have been obtained with erythromycin, doxycycline, gentamicin, quinolones, and trimetoprim-sulfamethoxazole (TMP-SMZ), and azithromycin (6). The aim of this study was to systematically review the articles which dealt with CSD case reports from Turkey published in national and international journals in the last 18 years using a pooled-analysis method.

\section{MATERIALS AND METHODS}

The articles on CSD published between 1996 and 2013 were retrieved by searching four national (Ulakbim Turkish Medical Literature Databases ${ }^{*}$ ) and three international databases (PubMed, Science Citation Index (SCI) and Google scholar). The keywords, such as cat scratch disease, granulomatous necrotizing lymphadenopathy and lymphadenitis were determined for the national databases. The keyword "Turkey" was added to these words for international databases. All of the retrieved articles were in case report form. The full texts of these articles have been reached, and the articles published before 1996 were excluded.

*http://www.turkishmedline.com, http://medline.pleksus.com.tr and www.atifdizini.com 
Demographic data of the patients including age, sex, and presence of risk factors and history of illness, symptoms, clinical findings, laboratory results, and therapeutic features were obtained from the articles.

Descriptive and frequency statistical analyses were performed by using the Statistical Package for the Social Science (SPSS) for Windows, version 15.0 software (SPSS, Chicago, IL, USA).

\section{RESULTS}

When the seven databases were screened with using specified keywords, 16 articles (4 international and 12 national) have been retrieved (7-22). However, when the articles were evaluated according to the clinic, seven $(38.8 \%)$, five $(27.7 \%)$ and two $(11.1 \%)$ cases were published by official researchers from the Department of Infectious Diseases and Clinical Microbiology, Pediatrics and Ophthalmology, respectively. The demographic data of the patients are presented in Table 1.

In total CSD has been identified in 18 patients in these articles. Seven $(38.8 \%)$ patients were female and $11(61.2 \%)$ were male, and the male to female ratio was determined as $1.57: 1$. The mean age of the patients was $23.9 \pm 15$ years (range 5-55 years) and half of the patients were $<18$ years. Cat exposure was reported in $14(77.7 \%)$ patients. Of 14 patients with known cat exposure, $3(21.4 \%)$ were long-time cat owners and $11(78.6 \%)$ reported only recently coming into contact with a cat. The interval between the animal contact and the onset of LAP or other constitutional symptoms ranged from 10 to 240 days (median 60 days). However, the median duration of symptoms before admission was 21 days (range 5-180 days).
As seen in Table 1, the most common clinicopathologic subtypes of CSD are regional lymphadenitis $(n=9)$, hepatosplenic $(n=3)$ and neuroretinitis $(n=2)$. None of them were known to be immunocompromised. The most common complaints of the patients were swelling (94.4\%), fever (61.2\%) and weakness (50\%). On exam, the most common signs were LAP (94.4\%), fever (55\%), splenomegaly, and skin eruption (16.6\%). The complaints and signs of the patients are shown in Table 2. Painful LAP was identified in 8 (44.4\%) cases. The regional distribution of lymph node involvement, as seen in Table 3 , is indicated in $94.4 \%$ of the cases, and most commonly affected regions were axillary (50\%) and cervical (22.2\%). While lymph node involvement was not detected in 2 patients, more than one lymph node involvement was observed in 5 (27.7\%) of the patients, and the size of lymphadenpathies were between $1 \times 1 \mathrm{~cm}$ and $7 \times 5 \mathrm{~cm}$.

Laboratory findings of CSD are variable and leukocytosis and anaemia were seen as hematological disorders. While total white blood cell count was studied in all of the patients, leukocytosis was observed in $27.7 \%$ of the patients. Peripheral blood smear was made in $5(27.7 \%)$ patients, and lymphocytosis was identified in $1(20 \%)$ and atypical lymphocytes were identified in none of them. Anaemia was determined in $36.3 \%(n=4 / 11)$ of the male patients and $14.3 \%(n=1 / 7)$ of the female patients, and thrombocytopenia was not observed in any patient. High erythrocyte sedimentation rate (ESR) and C-reactive protein (CRP) levels were measured in $47 \%$ and $40 \%$ of the patients, respectively (Table 4). The other biochemical parameters were within normal range in all patients. The serology of brucella, toxoplasma, cytomegalovirus (CMV), and human immune deficiency virus (HIV) were negative in examined patients.

Table 1. The demographic data of the patients with CSD $(N=18)$

\begin{tabular}{|c|c|c|c|c|c|c|c|}
\hline Case & Age & Sex & Admission time (d) & Contact with cats & Serology for $B$. henselae & Subtype of cat scratch disease & Result \\
\hline 1 & 15 & M & 21 & Yes & Untested & Neuroretinitis & Recovery \\
\hline 2 & 9 & M & 21 & Yes & Untested & Lymphadenitis & Recovery \\
\hline 3 & 16 & M & 7 & No & Untested & Neuroretinitis + Retinal detachment & Recovery \\
\hline 4 & 13 & M & 21 & Yes & IgG positive & Hepatosplenic & Recovery \\
\hline 5 & 10 & M & 10 & Yes & Untested & Hepatosplenic & Recovery \\
\hline 6 & 30 & M & 180 & Yes & Untested & Lymphadenitis & Recovery \\
\hline 7 & 44 & $\mathrm{~F}$ & 14 & Yes & Untested & Mammary & Recovery \\
\hline 8 & U & M & U & Yes & IgG positive (1/128) & Fever of unknown origin & Recovery \\
\hline 9 & 20 & $\mathrm{~F}$ & U & Yes & Untested & Lymphadenitis & Relapse \\
\hline 10 & 42 & $\mathrm{~F}$ & 10 & No & Untested & Sialadenitis + Salivary gland abscess & Recovery \\
\hline 11 & 37 & M & 21 & Yes & Untested & Lymphadenitis & Recovery \\
\hline 12 & 38 & $\mathrm{~F}$ & 90 & Yes & Untested & Lymphadenitis & Recovery \\
\hline 13 & 55 & $\mathrm{~F}$ & 60 & Yes & Untested & Lymphadenitis & Recovery \\
\hline 14 & 34 & $\mathrm{~F}$ & 15 & Yes & Untested & Lymphadenitis & Recovery \\
\hline 15 & 12 & M & 14 & Yes & IgG positive $(1 / 2,048)$ & Hepatosplenic & Recovery \\
\hline 16 & 5 & $\mathrm{~F}$ & 120 & No & Untested & Lymphadenitis & Recovery \\
\hline 17 & 15 & M & 22 & No & IgM positive $(1 / 1,024)$ & Lymphadenitis & Recovery \\
\hline 18 & 12 & M & 5 & Yes & $\lg G$ positive (1/320) & GBS + Acute transverse myelitis & Recovery \\
\hline
\end{tabular}

$\mathrm{U}$ - unknown, M - male, F - female, GBS - Guillain-Barre Syndrome 
Table 2. The symptoms and signs of the patients with CSD

\begin{tabular}{|l|c|}
\hline \multicolumn{2}{|l|}{$\mathbf{n}(\%)$} \\
\hline Symptoms & $17(94.4)$ \\
\hline Swelling & $11(61.2)$ \\
\hline Fever & $9(50.0)$ \\
\hline Weakness & $4(22.2)$ \\
\hline Lack of appetite & $3(16.6)$ \\
\hline Skin rash & $2(11.1)$ \\
\hline Nausea & $2(11.1)$ \\
\hline Arthralgia & $2(11.1)$ \\
\hline Weight loss & $1(5.5)$ \\
\hline Cough & \\
\hline Signs & $17(94.4)$ \\
\hline Lymphadenopathy & $11(61.2)$ \\
\hline Fever & $3(16.6)$ \\
\hline Splenomegaly & $3(16.6)$ \\
\hline Skin rash & $2(11.1)$ \\
\hline Hepatosplenomegaly & \\
\hline
\end{tabular}

Table 3. The regional distribution of lymph node involvement

\begin{tabular}{|l|c|}
\hline & $\mathbf{n}(\%)$ \\
\hline Axillary & $9(50.0)$ \\
\hline Left & $4(22.2)$ \\
\hline Right & $4(22.2)$ \\
\hline Bilateral & $1(5.6)$ \\
\hline Cervical & $4(22.2)$ \\
\hline Right & $2(11.1)$ \\
\hline Bilateral & $2(11.1)$ \\
\hline Inguinal & $1(5.6)$ \\
\hline Submandibular & $1(5.6)$ \\
\hline Supraclavicular & $1(5.6)$ \\
\hline Paraaortic & $1(5.6)$ \\
\hline More than one region & $5(27.7)$ \\
\hline
\end{tabular}

Table 4. The laboratory findings of the patients

\begin{tabular}{|c|c|}
\hline & $\mathrm{n}(\%)$ \\
\hline \multicolumn{2}{|c|}{ Total white blood cell count $/ \mathrm{mm}^{3}$} \\
\hline $4,000-10,000$ & $13(72.3)$ \\
\hline$>10,000$ & $5(27.7)$ \\
\hline \multicolumn{2}{|l|}{ Hemoglobin } \\
\hline Female $<12 \mathrm{~g} / \mathrm{dl}$ & $1 / 7(14.3)$ \\
\hline Male $<13,5 \mathrm{~g} / \mathrm{dl}$ & $4 / 11(36.3)$ \\
\hline $\mathrm{ESR}>20 \mathrm{~mm} / \mathrm{h}$ & $8 / 17(47.0)$ \\
\hline $\mathrm{CRP}>5 \mathrm{mg} / \mathrm{dl}$ & $6 / 15(40.0)$ \\
\hline
\end{tabular}

ESR - Erythrocyte sedimentation rate, CRP - C-reactive protein

CSD was identified by using clinical findings and/or serology and/or pathology confirmation. The IFA test for $B$. henselae was positive in $5(27.7 \%)$, and lymph node biopsies were obtained
Table 5. Treatments of the patients with CSD

\begin{tabular}{|c|c|}
\hline & $\mathrm{n}(\%)$ \\
\hline \multicolumn{2}{|l|}{ Antibiotics } \\
\hline Azithromycin & $6(33.3)$ \\
\hline Doxycycline & $1(5.5)$ \\
\hline TMP-SMZ & $1(5.5)$ \\
\hline Clarithromycin & $1(5.5)$ \\
\hline Ciprofloxacin & $1(5.5)$ \\
\hline \multicolumn{2}{|l|}{ Combination antibiotic therapy } \\
\hline Rifampicin + TMP-SMZ & $1(5.5)$ \\
\hline Cefazolin + Clarithromycin & $1(5.5)$ \\
\hline Rifampicin + Azithromycin & $1(5.5)$ \\
\hline Rifampicin + Doxycycline & $1(5.5)$ \\
\hline \multicolumn{2}{|l|}{ Others } \\
\hline Prednizolon & $1(5.5)$ \\
\hline IVIG + Prednizolon + Rifampicin + Doxycycline & $1(5.5)$ \\
\hline No drug used & $3(16.6)$ \\
\hline
\end{tabular}

TMP-SMZ - Trimetoprim-sulfamethoxazole, IVIG - Intravenous immunoglobulin

from $12(66.6 \%)$ patients and most of them reported as granulomatous lymphadenitis.

Before the diagnosis, $8(44.4 \%)$ patients had received a treatment of antibiotics by primary and/or secondary healthcare physicians. Treatments administered to the patients are shown in Table 5. All patients recovered without sequelae and relapse, except one.

\section{DISCUSSION}

CSD was first described as a clinical entity in 1931 and since 1950 many case reports have been published with reference to, but without characterization of an aetiological agent $(2,23)$. The association between $B$. henselae and CSD was first made by Regnery et al. (24) in 1992 in a study demonstrating that sera from CSD patients reacted with antigen prepared from the bacterium. From an epidemiological point of view, $87-99 \%$ of the patients report some contact with cats, although the exact mechanism of cat-to-human transmission remains partly unknown, a scratch and/or bite were documented in around a half of the episodes $(6,25)$. In this study, cat contact was determined in $77.7 \%$ of the patients. More than 24,000 cases of CSD are annually reported in the USA, resulting in more than 2,000 annual hospitalizations, with a rate of $0.86 / 100,000$ hospitalizations (26). While this ratio is approximately $2 / 100,000$ in Holland (27), comparable data for our country are not yet available. Males are more commonly affected than females, and the disease is almost always identified in patients younger than 21 years (28). In Murakami et al. (29) study, $79 \%$ of episodes occurred under the age of 18 . However, in the present study the median age was 16 years and $61.2 \%$ of the patients were male. Similar results were found by Ben-Ami et al. (4) in Israel who found that the median age was 16 years and male to female ratio was $1.4: 1$ in non-elderly group. Although cases occur throughout the year, there is a seasonal preference in temperate climates, with the highest number of cases occurring between September and March (6). The link between seasons and 
CSD incidence has been described in the USA, Japan and France with increased incidence in autumn and a decrease in spring (30). This may be related to the biological cycle of cat fleas, which may have a role in the transmission of $B$. henselae to kittens. Cats usually become pregnant in spring or early autumn, gestation lasting about nine weeks and warning six to nine weeks. Therefore, kittens come in contact with children and possible transmission of CSD usually occurs from late summer and midwinter (1). We do not have information about this situation in this study group or in Turkey.

The severity and presentation of the disease is related to immune status. In general, immunocompetent patients who are otherwise healthy tend to present with typical CSD and patients who are immunocompromised tend to have systemic disease (31). The incubation period of CSD is estimated to be 7-15 days; some local nonpruritic papules or papules and vesicles may follow the inoculation lesion and precede the characteristic regional lymph node involvement (25). In typical form, regional LAP is the hallmark of the disease and appears proximal to the inoculation site about two weeks after the introduction of organism into the skin. LAP commonly involves axillary nodes, followed by cervical and inguinal regions. Occasionally patients present with several enlarged nodes in the same anatomical region, but rarely with generalized LAP (32). LAPs are tender and eventually may suppurate (5), and usually resolve in 1-4 months, but may persist for as long as 1-3 years (32). Despite the impressive physical findings, patients with typical form usually do not appear ill and lack constitutional symptoms. Approximately one third to one half of patients have fever. About one third of patients have fatigue and malaise, and a minority exhibit other signs and symptoms, including hepatosplenomegaly, skin rash, headache, sore throat, nausea, abdominal pain, and anorexia (6). In this study, half of the patients were presented with the most common symptoms swelling and fever.

Hepatosplenic CSD is a clinical entity with well-documented clinical and radiological features (33). Most of these patients complain of abdominal pain. Hepatosplenomegaly and LAP may be absent. Ultrasound and computed tomography may be used to reveal lesions representing microabscesses (31). In this study group, $16.6 \%$ of the patients were with hepatosplenic CSD and they have also microabscesses in the spleen. Dissemination into the ocular region can give an atypical presentation of CSD as Perinaud's oculoglandular syndrome. This is seen in $5-6 \%$ of cases and it is characterized by conjunctivitis, conjunctival granuloma and ipsilateral periauricular LAP. Other ocular manifestations include neuroretinitis, papillitis, optic neuritis, and focal retinochoroiditis (32). Neuroretinitis appears to be the most common posterior segment complication of CSD, and is usually unilateral, although patients with unilateral visual loss, bilateral optic disk swelling and macular star formation have been reported $(5,7$, 9). In this study group, neuroretinitis was determined in $11.1 \%$ of the patients. Another unusual manifestation of CSD is breast involvement. It often manifests as a solitary, palpable breast mass within the tail of the breast tissue, associated axillary LAP is variably present. The inoculation site might be on the hand, arm or chest (6). Surgical biopsy is usually required, as in our patient, to exclude the possibility of malignant neoplasm (13). Encephalopathy is the most frequent neurological manifestation of the disease, followed by cranial or peripheral nerve involve- ment. Other forms of central nervous system involvement may include meningitis, encephalitis and transverse myelitis. These manifestations occur in $1-7 \%$ of the patients (31). Most of the patients are children younger than 18 years (6). Seizures are the most common initial symptom, although headache, mental status change, delirium, and coma also might occur. Cerebrospinal fluid evaluation might show mild pleocytosis and elevated protein level. Recovery is usually rapid and occurs within 2 to 14 days of the illness, and in general all patients recover completely within a year (31). In the present study, transverse myelitis and Guillain-Barre syndrome associated with CSD developed in one patient. Moreover, in a recent series prolonged fever of unknown origin (FUO) was the predominating sign in $2.8 \%$ of 130 cases; around $30 \%$ of these patients with a documented serological $B$. henselae infection lacked any LAP, as our patient (29). However, FUO was reported in nearly $8 \%$ of elderly patients in Ben-Ami et al. study (4) and in $4.8 \%$ of patients in the study by Jacobs and Schutze (34). These data indicate that $B$. henselae infection should be considered in the differential diagnosis of FUO in all patients, especially if a history of cat exposure is elicited.

The first step in diagnosis of CSD is a careful history with attention paid to patient contact with cats. A careful physical examination, including scrutiny of the hands, arms, face, chest, and scalp for possible inoculation sites, is invaluable (6). Routine haematologic and biochemistry laboratory testing is usually not very useful: hepatic transaminases may be elevated in the rare cases of systemic involvement (25). However, leukocytosis, mild anaemia and elevated ESR have already been described by Huarcaya et al. (2) in Peru, and elevated serum alkaline phosphatase level, often the only abnormal laboratory value in hepatosplenik CSD, was described by Rocco et al. (35). In the present study leukocytosis, elevated ESR and CRP were found in 27.7\%, 44.4\% and $33.3 \%$ of the patients, respectively.

Since $B$. henselae was identified as the aetiologic agent of CSD several diagnostic laboratory procedures have been developed. Culture is generally not relied on for the diagnosis of CSD, as the organism is very fastidious, slow growing and difficult to culture in most laboratory settings (6). The polymerase chain reaction is a rapid and specific method of detecting the organism in clinical samples but requires appropriate laboratory facilities and equipment. For histopathologic and immunohistochemical examination lymph node excision or biopsy is required. Therefore, for many clinical laboratories the most practical diagnostic method of confirming clinically suspected CSD is serologic testing (36). Serology can be performed by IFA and EIA. IgM antibodies against B. henselae are seldom found even in the early stages of $\mathrm{CSD}$, and negative results do not exclude the presence of acute disease (37). IgG titers less than 1/64 suggest the patient does not have current Bartonella infection. Titers between 1/64-1/256 represent possible infection; repeated testing should be performed in these patients in 10 to 14 days. Titers greater than $1 / 256$ strongly suggest active or recent infection (5). Barka et al. (38) described EIA for the detection of $B$. henselae-reactive $\operatorname{IgG}, \operatorname{IgM}$, and $\operatorname{IgA}$ antibodies and suggested that EIA was highly specific and more sensitive $(95 \%)$ ) than IFA. In contrast, serological investigations performed by Szelc-Kelly et al. (39) showed that the IFA measuring of IgG antibodies was the most sensitive ( 83 to $93 \%$ ) and the most specific (98\%) serologic test and that IgG EIA is not sensitive enough (16 to $35 \%$ ) for use in the clinical diagnosis of 
CSD. Similar results were also found in Israel (40). In instances in which serological results fail to confirm the diagnosis of CSD, lymph node excision and the performance of histopathologic and molecular diagnostic procedures are recommended (37). In the present study 5 patients (27.7\%) were evaluated serologically, IgG and IgM positivity was detected in 4 and 1 patient, respectively.

Tissue biopsy is one of the most useful ways to diagnose CSD and to exclude other causes of the illness. The histopathologic descriptions during the illness depend on the stage of it. At the beginning a lymphoid hyperplasia with arteriolar proliferation is expected, finally the characteristic CSD star-shaped conformation with multiple microabscesses will appear, with the presence of granulomas as microabscesses in a combined fashion (2). Organisms may be seen within histiocytes and in necrotic areas and thrombosed blood vessels (27). The Warthin-Starry silver staining has proven valuable in the detection of $B$. henselae. The stain was originally used to visualize spirochetes and reveals brown to black bacilli against a background of pale yellow to amber (31). B. henselae may be detected by this staining during the early stages of LAP, but they are rarely detected in the later granulomatous stage of inflammation $(2,37)$. However, Demers et al. (41) reported that this method lacks sensitivity, and positive results were obtained for only $12.5 \%$ of the patients. In this study, histopathological evaluation was performed in $66.6 \%$ of the patients and the Warthin-Starry silver staining was carried out in only two cases.

The differential diagnosis of typical CSD includes many causes of LAP. Painful LAP points to infection, and include bacterial adenitis, such as Staphylococcus aureus, group A betahemolytic streptococci and Brucella spp., viral LAP (CMV, HIV and Epstein-Barr virus), LAP with cutaneous lesion (Nocardia spp., Francisella tularensis, Yersinia pestis, Erysipelothrix rhusiopathiae, Borrelia burgdorferi and typical or atypical mycobacterial infection), protozoan (toxoplasmosis), and rarely fungal such as histoplasmosis and sporotrichosis $(32,42)$. In the case of atypical presentation or prolonged systemic symptoms lymphoma and other neoplasms should be suspected and lymph node biopsy done to exclude malignancy.

CSD is usually a self-limited disease, therefore, the effects of antibiotics have been difficult to evaluate without placebo controlled trials. Ironically, a number of antibiotics with good in vitro activity against $B$. henselae have not had clear-cut benefits in the treatment of CSD. The lack of intracellular penetration and the sequestration of antibiotic within the lymph node may provide a partial explanation for the observed phenomenon (43). Currently, most Bartonella spp. isolates appear to be susceptible in vitro to a wide range of beta-lactams as well as to rifampicin, erythromycin and tetracyclines, while sensitivity to clindamycin, quinolones and TMP-SMZ seems more variable $(25,42)$. Unfortunately, a remarkable discordance between in vitro and in vivo activity of several molecules, especially penicillin, has been demonstrated (44). However, azithromycin penetrates into both macrophages and neutrophils, and it has also been suggested that phagocytes may transport azithromycin into areas of inflammation and infection. Furthermore, a separate experiment demonstrated that the concentration of azithromycin remained high within the phagocytes when drugs were removed from the incubation medium (43) so that azithromycin is the preferred antibiotic in CSD (45). In the present study, azithromycin was also administered to $33.3 \%$ of the patients. Multiple antibiotic cycles carried out with different compounds did not seem to significantly modify the disease course in terms of time and mode of cure, as in our cases. Therefore, the role and mode of antimicrobial therapy in the setting of CSD require further investigation. In addition, corticosteroid adjuncts have been recently suggested for patients with a long-lasting course, whenever an exaggerated immune response has been found, but no controlled data are available yet (25). On the other hand, needle drainage is recommended over incision and drainage of involved lymph nodes, owing to the chance of forming a persistent draining sinus tract. Surgical excision of deep lesions is not required, although surgical biopsy might be needed to obtain diagnostic tissue (6).

In conclusion, regional LAP is the hallmark of the CSD. Therefore, $B$. henselae should always be in the differential diagnosis of patients presenting with a tender swollen lymph node in all age groups. The diagnosis of CSD can be easily overlooked if the clinician fails to obtain an adequate history, especially in the case of atypical syndromes or in the case of adults with typical syndromes whose clinicians are inexperienced with CSD. However, CSD may be more prevalent than realized, and an unnecessary biopsy may be avoided on the basis of serology results. In addition, preventive measures would require avoidance of close contacts with cats and cat fleas, with increased awareness of the risk of cat scratches.

\section{Conflict of Interests}

None declared

\section{REFERENCES}

1. Karpathios T, Golphinos C, Psychou P, Garoufi A, Papadimitriou A, Nicolaidou P. Cat scratch disease in Greece. Arch Dis Child. 1998 Jan;78(1):64-6.

2. Huarcaya E, Maguina C, Merello J, Cok J, Birtles R, Infante B, et al. A prospective study of cat scratch disease in Lima-Peru. Rev Inst Med Trop Sao Paulo. 2002 Nov-Dec;44(6):325-30.

3. Zangwill KM, Hamilton DH, Perkins BA, Regnery RL, Plikaytis BD, Hadler JL, et al. Cat scratch disease in Connecticut. Epidemiology, risk factors, and evaluation of a new diagnostic test. N Engl J Med. $1993 \mathrm{Jul}$ 1;329(1):8-13.

4. Ben-Ami R, Ephros M, Avidor B, Katchman E, Varon M, Leibowitz C, et al. Cat scratch disease in elderly patients. Clin Infect Dis. 2005 Oct 1;41(7):969-74.

5. Klotz SA, Ianas V, Elliott SP. Cat scratch disease. Am Fam Physician. 2011 Jan 15;83 (2):152-5.

6. Lamps LW, Scott MA. Cat scratch disease: historic, clinical, and pathologic perspectives. Am J Clin Pathol. 2004 Jun;121 Suppl:S71-80.

7. Altay Y, Kalayci D, Sarikatipoğlu H, Hasiripi H. Neuroretinitis associated with cat-scratch disease: a case report. T Klin Oftalmoloji. 1996;5(4):3802. (In Turkish.)

8. Köksal Y, İnce E, Ulukol B, Çiftçi E, Azık F, Kuzu I, et al. Cat scratch disease: a case report. Ankara Üniversitesi Tıp Fakültesi Mecmuası 2001;54(2):177-80. (In Turkish.)

9. Saatçi AO, Öner FH, Kargi A, Kavukcu S. Unilateral neuroretinitis and serous retinal detachment in cat scratch disease. Korean J Ophthalmol. 2002 Jun;16(1):43-6.

10. Tükek SS, İslim F, Tükek T, Ağan M. A case who has granulomatous lymphadenopathy which mimicked malignant lymphoma: cat scratch disease in differential diagnosis. İst Tıp Fak Mecmuası. 2003;66(4):25660. (In Turkish.)

11. Kara B, Uçan S, Basim B, Erçin C, Arısoy ES. A case report of hepatosplenic cat scratch disease. Çocuk Dergisi. 2004;4(1):58-60. (In Turkish.)

12. Eroğlu C, Çandir N, Dervişoğlu A, Kefeli M. A case of cat scratch disease. Mikrobiyol Bul. 2007 Oct;41(4):603-6. (In Turkish.) 
13. Böyük A, Üstün C, Arslan Solmaz Ö, Altınsoy HB, Banlı O. Rare case misinterpreted as breast cancer: cat scratch disease. Firat Tip Dergisi. 2009;14(4):268-70. (In Turkish.)

14. Çelebi B, Yalçin E, Babür C. Fever of unknown origin and detection of Bartonella henselae IgG seropositivity: a case report. Mikrobiyol Bul. 2010 Jun;44(3):489-94. (In Turkish.)

15. Yapıсı K, Karahocagil MK, Kösem M, Akdeniz N, GörkemY. Recurring cat-scratch disease: a case report. Tıp Araştırmaları Dergisi. 2010;8(1):436. (In Turkish.)

16. Aydil U, Özçelik T, Kutluay L. Sialadenitis and salivary gland abscess refractory to medical treatment: an atypical presentation of cat scratch disease. Gazi Med J. 2011;22(3):91-3 (In Turkish.)

17. Bölük G, Mıstık R, Helvacı S, Yalçinkaya U, Öztürk Nazlığlu H. Three probable cat scratch disease cases treated with azithromycin. Flora. 2011;16(3):135-8. (In Turkish.)

18. Korkmaz P, Naz H, Gücüyener MN, Cağlan-Cevik F, Aykın N. Cat-scratch disease: a case report. Klimik Dergisi. 2011;24(2):116-8. (In Turkish.)

19. Akgün M, Belet N, Karlı A, Bilgici MC, Sensoy G. Visceral involvemen and inguinal lymphadenopathy: a rare case of cat scratch disease. J Pediatr Inf. 2012;6(3):109-11. (In Turkish.)

20. Senayli A, Koseoglu RD, Senayli Y. Atypical and long-term manifestation of cat scratch disease with axillary lymphadenopathies. J Contemp Med. 2012;2(1):22-5.

21. Özsürekci Y, Karadağ Öncel E, Cengiz AB, Kara A. Axillary lymphadenitis in an adolescent patient. J Pediatr Inf. 2012;6(4):158-60. (In Turkish.)

22. Carman KB, Yimenicioglu S, Ekici A, Yakut A, Dinleyici EC. Coexistence of acute transverse myelitis and Guillain-Barre' syndrome associated with Bartonella henselae infection. Paediatr Int Child Health. 2013 Aug;33(3):190-2.

23. Çelebi B. Bartonella henselae and its infections. Mikrobiyol Bul. 2008 Jan;42(1):163-75. (In Turkish.)

24. Regnery RL, Anderson BE, Clarridge JE 3rd, Rodriquez-Barradas MC, Jones DC, Carr JH. Characterization of a novel Rochalimaea species, R. henselae sp. nov., isolated from blood of a febrile, human immunodeficiency virus-positive patient. J Clin Microbiol. 1992 Feb;30(2):265-74.

25. Manfredi R, Sabbatani S. Bartonellosis: suggestive case reports in adult and pediatric patients and therapeutic issues. Braz J Infect Dis. 2006 Dec;10(6):411-5.

26. Jackson LA, Perkins BA, Wenger JD. Cat scratch disease in the United States: an analysis of three national databases. Am J Public Health. 1993 Dec;83(12):1707-11.

27. Van der Veer-Meerkerk M, Van Zaanen HC. Visceral involvement in an immunocompetent male: a rare presentation of cat scratch disease. Neth J Med. 2008 Apr;66(4):160-2.

28. Montone KT. Infectious disease of the head and neck. Am J Clin Pathol. 2007;128(1):35-67.

29. Murakami K, Tsukahara M, Tsuneoka H, Iino H, Ishida C, Tsujino K, et al. Cat scratch disease: analysis of 130 seropositive cases. J Infect Chemoter. 2002 Dec;8(4):349-52.

30. Sanguinetti-Morelli D, Angelakis E, Richet H, Davoust B, Rolain JM, Raoult D. Seasonality of cat-scratch disease, France, 1999-2009. Emerg Infect Dis. 2011 Apr;17(4):705-7.
31. Anderson BE, Neuman MA. Bartonella spp. as emerging human pathogens. Clin Microbiol Rev. 1997 Apr;10(2):203-19.

32. Wilson J, Saltzman D, Jimenez C, Skorupskaite K, Sabeti M, Balzer, C. Cat scratch disease in a teenager. Proc UCLA Healthcare. 2012;16.

33. Arisoy ES, Correa AG, Wagner ML, Kaplan SL. Hepatosplenic cat-scratch disease in children: selected clinical features and treatment. Clin Infect Dis. 1999 Apr;28(4):778-84

34. Jacobs RF, Schutze GE. Bartonella henselae as a cause of prolonged fever and fever of unknown origin in children. Clin Infect Dis. 1998 Jan;26(1):80-4.

35. Rocco VK, Roman RJ, Eigenbrodt EH. Cat scratch disease: report of a case with hepatic lesions and a brief review of the literature. Gastroenterology. 1985 Dec;89(6):1400-6.

36. Sander A, Posselt M, Oberle K, Bredt W. Seroprevalence of antibodies to Bartonella henselae in patients with cat scratch disease and in healthy controls: evaluation and comparison of two commercial serological tests. Clin Diagn Lab Immunol. 1998 Jul;5(4):486-90.

37. Ridder GJ, Boedeker CC, Technau-Ihling K, Grunow R, Sander A. Role of cat-scratch disease in lymphadenopathy in the head and neck. Clin Infect Dis. 2002 Sep 15;35(6):643-9.

38. Barka NE, Hadfield T, Patnaik M, Schwartzman WA, Peter JB. EIA for detection of Rochalimaea henselae-reactive IgG, IgM and IgA antibodies in patients with suspected cat-scratch disease. J Infect Dis. 1993 Jun;167(6):1503-4.

39. Szelc-Kelly CM, Goral S, Perez-Perez GI, Perkins BA, Regnery RL, Edwards KM. Serologic response to Bartonella and Afipia antigens in patients with cat-scratch disease. Pediatrics. 1995 Dec;96(6):1137-42.

40. Metzkor-Cotter E, Kletter Y, Avidor B, Varon M, Golan Y, Ephros M, et al. Long-term serological analysis and clinical follow-up of patients with cat scratch disease. Clin Infect Dis. 2003 Nov 1;37(9):1149-54.

41. Demers DM, Bass JW, Vincent JM, Person DA, Noyes DK, Staege CM, et al. Cat- scratch disease in Hawaii: etiology and seroepidemiology. J Pediatr. 1995 Jul;127(1):23-6.

42. Slater LN, Welch DF. Bartonella, including cat scratch disease. In: Mandell GL, Bennett JE, Dolin R, editors. Principles and practice of infectious diseases. 7th ed. Philadelphia, Pa: Elsevier Churchill Livingstone; 2010. p. 2995-3005.

43. Chia JK, Nakata MM, Lami JL, Park SS, Ding JC. Azithromycin for the treatment of cat-scratch disease. Clin Infect Dis. 1998 Jan;26(1):193-4.

44. Maurin M, Gasquet S, Ducco C, Raoult D. MICs of 28 antibiotic compounds to 14 Bartonella (formerly Rochalimaea) isolates. Antimicrob Agents Chemother. 1995 Nov;39(11):2387-91.

45. Bass JW, Freitas BC, Freitas AD, Sisler CL, Chan DS, Vincent JM, et al. Prospective randomized double blind placebo-controlled evaluation of azithromycin for treatment of cat-scratch disease. Pediatr Infect Dis J. 1998 Jun;17(6):447-52.

Received May 7, 2014 Accepted in revised form March 18, 2015 